\title{
QuitPuff: A Simple Method Using Lipid Peroxidative Changes in Saliva to Assess the Risk of Oral Precancerous Lesions and Oral Squamous Cell Carcinoma in Chronic Smokers
}

\begin{abstract}
Introduction: Smoking, the leading cause of oral cancer in India, kills over 5 people every hour. As high mortality is due to late diagnosis, early detection is vital. Free radical-induced lipid peroxidation (LP) is known to promote multistep oral carcinogenesis. Free radicals generated by smoking damage polyunsaturated fatty acids releasing end product malondialdehyde (MDA). A simple, home-based test was devised to determine salivary MDA to assess early risk of oral precancer and cancer. It was hypothesized that heavier smokers would exhibit greater degree of salivary LP. Materials and Methods: A highly sensitive QuitPuff reagent was formulated which when heated with saliva, produces a color change, directly proportional to the amount of MDA. The MDA level was measured by matching the color change with a colorimetric LP index (LPI) chart. QuitPuff was tested on 500 subjects, validated using the gold standard, ultraviolet (UV) spectroscopy. Results: The mean LPI was consistently and significantly elevated $(P<0.001)$ in smokers with oral precancer and cancer (4.34) and smokers who smoked more than 20 (4.12), between 10 and 20 (3.43), and $<10$ cigarettes per day (2.43) as compared to nonsmokers (0.26). The mean LPIs of the test and validation methods correlated. Spearman's correlation indicated significant positive association between color changes and UV spectroscopy readings $(r=0.93)$. QuitPuff detected salivary MDA levels with 96\% accuracy. Conclusion: Smokers exhibited greater degree of salivary LP as compared to nonsmokers; the heavier the smoker, greater was the degree of LP. QuitPuff has great potential as a point-of-care test for oral precancer and cancer.
\end{abstract}

Keywords: Lipid peroxidation, oral cancer detection, oral cancer diagnosis, oral cancer in chronic smokers, salivary diagnostic test for oral cancer

\section{Introduction}

High mortality in oral cancer attributed mainly to late diagnosis

Oral cancer also known as mouth cancer is any cancerous tissue growth located in the oral cavity. ${ }^{[1]}$ It most commonly involves the tongue, floor of the mouth, cheek lining, gums, lips, or roof of the mouth. More than $90 \%$ of all oral cancers are squamous cell carcinoma. ${ }^{[2]}$

By country, the incidence of oral cancer is the highest in India, which accounts for almost one-third of cases found in the world. ${ }^{[1]}$ Over five people in India die every hour because of oral cancer. ${ }^{[3]}$ Public health centers and private hospitals have recognized oral cancer as a grave problem and efforts toward early

\footnotetext{
This is an open access journal, and articles are distributed under the terms of the Creative Commons Attribution-NonCommercial-ShareAlike 4.0 License, which allows others to remix, tweak, and build upon the work non-commercially, as long as appropriate credit is given and the new creations are licensed under the identical terms.
}

For reprints contact: WKHLRPMedknow_reprints@wolterskluwer.com detection and prevention can help reduce this burden.

The high prevalence of oral cancer in India is mainly due to the influence of tobacco and betel quid chewing. ${ }^{[4]}$ Greater than $90 \%$ of patients with oral cancer report using tobacco products. ${ }^{[5]}$ The incidence of oral cancer in patients who smoke and chew tobacco is 8.4 times greater than that of patients who do not. ${ }^{[6]}$

Globally, the 5-year mortality rate of oral cancer is approximately $50 \%$ and has not improved despite advances in diagnostic techniques and improvements in treatment modalities. ${ }^{[4]}$ The high mortality rate in oral cancer is attributed to late diagnosis, which is either due to lack of knowledge or access to medical care..$^{[1,2,7]}$ Most patients seek help only in later stages when symptoms such as pain, ulceration, or a neck mass appear. ${ }^{[1]}$

How to cite this article: Shamsher N, Prabhu C. QuitPuff: A simple method using lipid peroxidative changes in saliva to assess the risk of oral precancerous lesions and oral squamous cell carcinoma in chronic smokers. Indian J Med Paediatr Oncol 2020;41:670-6.

\section{Nikhiya Shamsher ${ }^{1}$, Chaithanya Prabhu²}

${ }^{1}$ Student, Stanford University, California, USA, ${ }^{2}$ Department of Biotechnology, M.S Ramaiah Institute of Technology,

Bengaluru, Karnataka, India

Submitted: 26-May-2019

Revised: 29-May-2020

Accepted: 30-Jun-2020

Published: 29-Oct-2020

Address for correspondence:

Ms. Nikhiya Shamsher,

Stanford University, 450 Jane

Stanford Way, California 94305, USA.

E-mail: nikhiyashamsher@ gmail.com

Access this article online

Website: www.ijmpo.org

DOI: 10.4103/ijmpo.ijmpo_127_19

Quick Response Code:

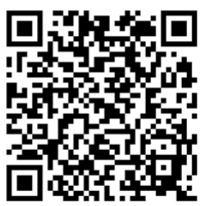


Detection of an oral cancer at Stage I carries a prognosis of $80 \%$ survival, while the same lesion at Stage III carries a prognosis of $20 \%$ survival ${ }^{[8]}$ This difference could affect not only the quality of life for the patients, but also the cost of the medical treatment. Thus, there is a need for improvement in early risk detection of oral carcinomas, because in the initial and precancerous stages, treatment is more effective and morbidity is minimal.

Link between free radicals, lipid peroxidation, and oral precancer and cancer

Free radical-induced lipid peroxidation (LP) has been implicated in the pathogenesis of oral cancer. ${ }^{[9-13]}$ Smoking generates free radicals and reactive oxygen species (ROS). ROS-induced cell damage causes LP. It most commonly affects polyunsaturated fatty acids, which causes alteration in the structure and function of cell membranes and also initiates and promotes the multistep process of carcinogenesis. ${ }^{[10]}$

Malondialdehyde (MDA) is the end product of LP and can be used as a marker for assessing the extent of LP..$^{[9-13]}$ MDA is mutagenic and genotoxic, as it readily reacts with deoxynucleosides to produce adducts that cause DNA damage. ${ }^{[1]}$ An increase in MDA concentrations in saliva has been widely reported in various oral precancers and cancers in the early stages. ${ }^{[9-13]}$ The salivary MDA in potentially malignant diseases is found to be in the range of $25-50 \mathrm{ng} / \mathrm{ml}$ and that in oral squamous cell carcinoma in the range of $50-100 \mathrm{ng} / \mathrm{ml} .^{[9,11,14]}$

In addition, previous studies have shown that salivary MDA could serve as a potential diagnostic marker, and that by measuring the salivary MDA level, we can measure the extent of LP and thereby assess the risk of a smoker toward developing oral precancer and oral cancer. ${ }^{[9,10,12-15]}$

With this background, we were motivated to investigate the relationship between smoking, LP, and oral cancer and hence we carried out our study. We hypothesized that the heavier the smoker, the greater the level of salivary LP and the higher the risk of developing oral precancer and cancer. To test our hypothesis, we devised a simple, quick, colorimetric, home-based test named QuitPuff to determine the salivary MDA levels in smokers.

\section{Materials and Methods}

In this study, a simple home-based diagnostic method named QuitPuff was developed for the determination of LP in saliva by simple means, i.e., through a visible color change which can be observed by naked eye.

2-Thiobarbituric acid (TBA) 98\% was purchased from Sigma-Aldrich; MDA tetrabutylammonium salt $96 \%$ pure was purchased from Sigma-Aldrich. Extra pure distilled water was used. Trichloroacetic acid 1\% and orthophosphoric acid $85 \%$ pure were purchased from Emplura.
The study was conducted on patients from two hospitals and a clinic. The sample analysis and experiments were conducted at a regulated research institution.

Preparation of malondialdehyde standards in saliva of healthy nonsmokers

As our diagnostic medium was saliva, the MDA standards were also prepared in saliva. Ten healthy subjects were selected in the age group of 30-45 years, with no prior history of smoking or tobacco chewing. To rule out any preexisting MDA, their saliva samples were sent to a regulated institution for MDA detection through liquid chromatography-mass spectroscopy (LCMS). The LCMS report confirmed the absence of MDA in all 10 samples collected from the healthy people.

$10 \mathrm{~mL}$ of unstimulated saliva was collected from each of the ten healthy subjects. MDA standards using saliva of each of the 10 healthy subjects were prepared in the concentrations of $500 \mathrm{ng} / \mathrm{mL}, 250 \mathrm{ng} / \mathrm{mL}, 100 \mathrm{ng} / \mathrm{mL}$, $50 \mathrm{ng} / \mathrm{mL}, 25 \mathrm{ng} / \mathrm{mL}$, and $5 \mathrm{ng} / \mathrm{mL}$.

\section{Preparation of the diagnostic QuitPuff reagent}

One molecule of MDA reacts with two molecules of TBA under high temperature and acidic conditions to produce a colored MDA-TBA adduct. This is the basic principle of TBARS assay which is the most widely employed assay used to determine LP. Although being accurate, these tests are not routinely done in laboratories. They are expensive, require technical skills, laboratories, and instrumentation, and sometimes need complex methods such as high-performance liquid chromatography or LCMS. Thus, they are fairly out of reach of ordinary people.

As the aim of our study was to develop a simple, home-based test, we explored the possibility of converting a complex laboratory-based TBARS assay into a simple colorimetric test that could be self-conducted by the user and the results could be interpreted by simply matching the color change in a sample of saliva to a color chart.

To formulate the most sensitive TBA reagent that would detect MDA concentrations as low as $5 \mathrm{ng} / \mathrm{mL}$, by producing a visible color change, MDA standards using saliva of 10 healthy subjects were prepared in the concentrations of $500 \mathrm{ng} / \mathrm{mL}, 250 \mathrm{ng} / \mathrm{mL}, 100 \mathrm{ng} / \mathrm{mL}$, $50 \mathrm{ng} / \mathrm{mL}, 25 \mathrm{ng} / \mathrm{mL}$ and $5 \mathrm{ng} / \mathrm{mL}$ and TBA reaction was performed using various TBA formulations that were adapted from previous studies. ${ }^{[16-20]}$ [Table 1].

As shown in Table 1, the formulation used in method 8 proved to be most sensitive, detecting MDA levels as low as $5 \mathrm{ng} / \mathrm{mL}$ by producing a visible color change. Thus, the QuitPuff TBA Reagent was prepared by dissolving $0.375 \mathrm{~g}$ of TBA in $85 \%$ orthophosphoric acid $(1 \mathrm{ml})$ and $1 \%$ trichloroacetic acid $(1 \mathrm{ml})$. 
Table 1: Derivation of the QuitPuff reagent

\begin{tabular}{|c|c|c|c|c|}
\hline Method no. & TBA formulation & TBA reaction & $\begin{array}{l}\text { Detection limit of } \\
\text { color change }\end{array}$ & $\begin{array}{l}\text { Adaptability as a } \\
\text { point-of-care }\end{array}$ \\
\hline Method 1 & $\begin{array}{l}\text { Formulation adapted from Ohkawa } \\
\text { et al. } .^{[16]}, 0.2 \mathrm{~mL} \text { of } 8.1 \% \text { sodium } \\
\text { dodecyl sulphate (SDS), } 1.5 \mathrm{~mL} 20 \% \\
\text { acetic acid at } \mathrm{pH} 3.5,1.5 \mathrm{~mL} \text { of } 0.8 \% \text { of } \\
\text { Thiobarbituric Acid (TBA) }\end{array}$ & $\begin{array}{l}0.2 \mathrm{~mL} \text { TBA reagent was added to } \\
0.2 \mathrm{ml} \text { of each of the MDA standards } \\
\text { as well as a saliva control and boiled } \\
\text { in water bath for } 1 \text { hour at } 95 \text { degree } \\
\text { Celsius. }\end{array}$ & $100 \mathrm{ng} / \mathrm{mL}$ & $\mathrm{x}$ \\
\hline Method 2 & $\begin{array}{l}\text { Formulation adapted from Buege } \\
\text { J.A and S.D. Aust et al. }{ }^{[17]}, 0.5 \% \\
\text { Thiobarbituric Acid, } 20 \% \text { Trichloro } \\
\text { Acetic acid, } 2.5 \mathrm{~N} \text { Hydrochloric acid }\end{array}$ & $\begin{array}{l}0.5 \mathrm{~mL} \text { TBA reagent was added to } 0.5 \\
\mathrm{~mL} \text { of each of the MDA standards as } \\
\text { well as a saliva control and heated in a } \\
\text { boiling water bath for } 20 \text { minutes. }\end{array}$ & $100 \mathrm{ng} / \mathrm{mL}$ & $\mathrm{x}$ \\
\hline Method 3 & $\begin{array}{l}\text { Formulation adapted from } \\
\text { Esterbauer H. et al. }{ }^{[18]}, 1 \mathrm{~mL} 0.37 \% \\
\text { Ethylenediaminetetraacetic-acid } \\
\text { (EDTA), } 1 \mathrm{~mL} 2 \% \text { Butylated } \\
\text { hydroxytoluene (BHT), } 2 \mathrm{~mL} 10 \% \\
\text { Trichloro Acetic Acid, } 1 \mathrm{ml} 0.67 \% \\
\text { Thiobarbituric Acid. }\end{array}$ & $\begin{array}{l}5 \mathrm{ml} \text { TBA reagent was added to } 1 \mathrm{ml} \text { of } \\
\text { each of the MDA standards as well as } \\
\text { a saliva control and heated in a boiling } \\
\text { water bath for } 10 \text { minutes. }\end{array}$ & $100 \mathrm{ng} / \mathrm{mL}$ & $\mathrm{x}$ \\
\hline Method 4 & $\begin{array}{l}\text { Formulation adapted from Uchiyama } \\
\mathrm{M} \text { and Midori Mihara M. }{ }^{[19]}, 3 \mathrm{~mL} \\
1 \% \text { Phosohoric acid, } 1 \mathrm{~mL} 0.6 \% \\
\text { Thiobarbituric acid aqueous solution }\end{array}$ & $\begin{array}{l}\text { TBA reagent was added to } 0.5 \mathrm{~mL} \text { of } \\
\text { each of the MDA standards as well as } \\
\text { a saliva control and heated in a boiling } \\
\text { water bath for } 45 \text { minutes. }\end{array}$ & $25 \mathrm{ng} / \mathrm{mL}$ & $\mathrm{x}$ \\
\hline Method 5 & $\begin{array}{l}\text { Formulation adapted from Asakawa } \\
\text { T. and Matsushita S. }{ }^{[20]}, 2 \mathrm{~mL} \text { of } 20 \% \\
\text { Trichloro Acetic acid containing } 20 \\
\text { umol Ferrous Sulphate, } 1 \mathrm{~mL} 0.67 \% \\
\text { Thiobarbituric acid }\end{array}$ & $\begin{array}{l}\text { TBA reagent was added to } 1 \mathrm{~mL} \text { of } \\
\text { each of the MDA standards as well as } \\
\text { a saliva control and heated in a boiling } \\
\text { water bath for } 30 \text { minutes. }\end{array}$ & $25 \mathrm{ng} / \mathrm{mL}$ & $\mathrm{x}$ \\
\hline Method 6 & $\begin{array}{l}\text { Formulation adapted from } \\
\text { experimentation } 0.1875 \mathrm{~g} \text { of } \\
\text { Thiobarbituric Acid in } 0.4562 \mathrm{~mL} \text { of } \\
\text { Acetic Acid, added distilled water to } \\
\text { bring the volume to } 50 \mathrm{~mL}\end{array}$ & $\begin{array}{l}2 \mathrm{~mL} \text { TBA reagent was added to } 1 \\
\mathrm{~mL} \text { of each of the MDA standards as } \\
\text { well as a saliva control and heated in a } \\
\text { boiling water bath for } 15 \text { minutes. }\end{array}$ & $\begin{array}{l}5 \mathrm{ng} / \mathrm{mL} \text {, color } \\
\text { change observed in } \\
\text { control }\end{array}$ & $\mathrm{x}$ \\
\hline Method 7 & $\begin{array}{l}\text { Formulation adapted from } \\
\text { experimentation. } 1 \mathrm{~mL} 0.375 \mathrm{~g} \text { of } \\
\text { Thiobarbituric Acid in } 1 \mathrm{~mL} 85 \% \text { Ortho- } \\
\text { Phosphoric Acid. }\end{array}$ & $\begin{array}{l}2 \mathrm{~mL} \text { TBA reagent was added to } 1 \\
\mathrm{~mL} \text { of each of the MDA standards as } \\
\text { well as a saliva control and heated in a } \\
\text { boiling water bath for } 15 \text { minutes. }\end{array}$ & $25 \mathrm{ng} / \mathrm{mL}$ & $\mathrm{x}$ \\
\hline Method 8 & $\begin{array}{l}\text { Formulation adapted from } \\
\text { experimentation } 0.375 \mathrm{~g} \text { of } \\
\text { Thiobarbituric Acid in } 1 \mathrm{~mL} 85 \% \text { Ortho- } \\
\text { Phosphoric Acid, } 1 \mathrm{~mL} 1 \% \text { Trichloro } \\
\text { Acetic Acid. }\end{array}$ & $\begin{array}{l}2 \mathrm{~mL} \text { TBA reagent was added to } 1 \\
\mathrm{~mL} \text { of each of the MDA standards as } \\
\text { well as a saliva control and heated in a } \\
\text { boiling water bath for } 15 \text { minutes. }\end{array}$ & $5 \mathrm{ng} / \mathrm{mL}$ & $\checkmark$ \\
\hline Method 9 & $\begin{array}{l}\text { Formulation adapted from } \\
\text { experimentation } 0.375 \mathrm{~g} \text { of TBA in } 1 \mathrm{~mL} \\
1 \% \text { Ascorbic Acid, } 1 \mathrm{~mL} 1 \% \text { Trichloro } \\
\text { Acetic Acid. }\end{array}$ & $\begin{array}{l}2 \mathrm{~mL} \text { TBA reagent was added to } 1 \\
\mathrm{~mL} \text { of each of the MDA standards as } \\
\text { well as a saliva control and heated in a } \\
\text { boiling water bath for } 15 \text { minutes. }\end{array}$ & $\begin{array}{l}5 \mathrm{ng} / \mathrm{mL} \text {, color } \\
\text { change observed in } \\
\text { control }\end{array}$ & $\mathrm{x}$ \\
\hline Method 10 & $\begin{array}{l}\text { Formulation adapted from } \\
\text { experimentation } 0.3 \mathrm{~g} \text { of TBA dissolved } \\
\text { in } 3 \mathrm{~mL} \text { of Dimethyl Sulfoxide (DMSO). }\end{array}$ & $\begin{array}{l}2 \mathrm{~mL} \text { TBA reagent was added to } 1 \\
\mathrm{~mL} \text { of each of the MDA standards as } \\
\text { well as a saliva control and heated in a } \\
\text { boiling water bath for } 15 \text { minutes. }\end{array}$ & $25 \mathrm{ng} / \mathrm{mL}$ & $\mathrm{x}$ \\
\hline
\end{tabular}

Thiobarbituric acid - Reaction on known standards using QuitPuff

Using the QuitPuff diagnostic TBA reagent, TBA reaction was carried out on the known standards of MDA to generate a visibly colored MDA-TBA adduct. $2 \mathrm{~mL}$ of TBA reagent was added to $1 \mathrm{~mL}$ of each of the six MDA standards as well as a saliva control. The mixtures were then heated in a boiling water bath for $15 \mathrm{~min}$ and the color change was observed. The color change was observed in a gradient, with A being the darkest and $\mathrm{F}$ being the lightest. The color of control in the saliva control remained unchanged [Figure 1a].

The colored samples were analyzed through ultraviolet (UV) visible spectroscopy and the absorbances were measured at $532 \mathrm{~nm}$. Based on the readings, a standard curve was prepared [Figure 1b]. The optical density was plotted along the Y-axis and the MDA concentration in $\mathrm{ng} / \mathrm{mL}$ was 
plotted along the $\mathrm{X}$-axis. The following linear equation was derived: $(\mathrm{Y}=0.0049 \mathrm{X}+0.1472)$.

Preparation of colorimetric chart or the lipid peroxidation index

Based on the color change and UV spectroscopy readings, a colorimetric chart was prepared [Figure 2]. The colors are numbered from zero to six and denote the LP index (LPI). The results can be interpreted by noting the LPI, which indicates the degree of LP, and thereby the risk status.

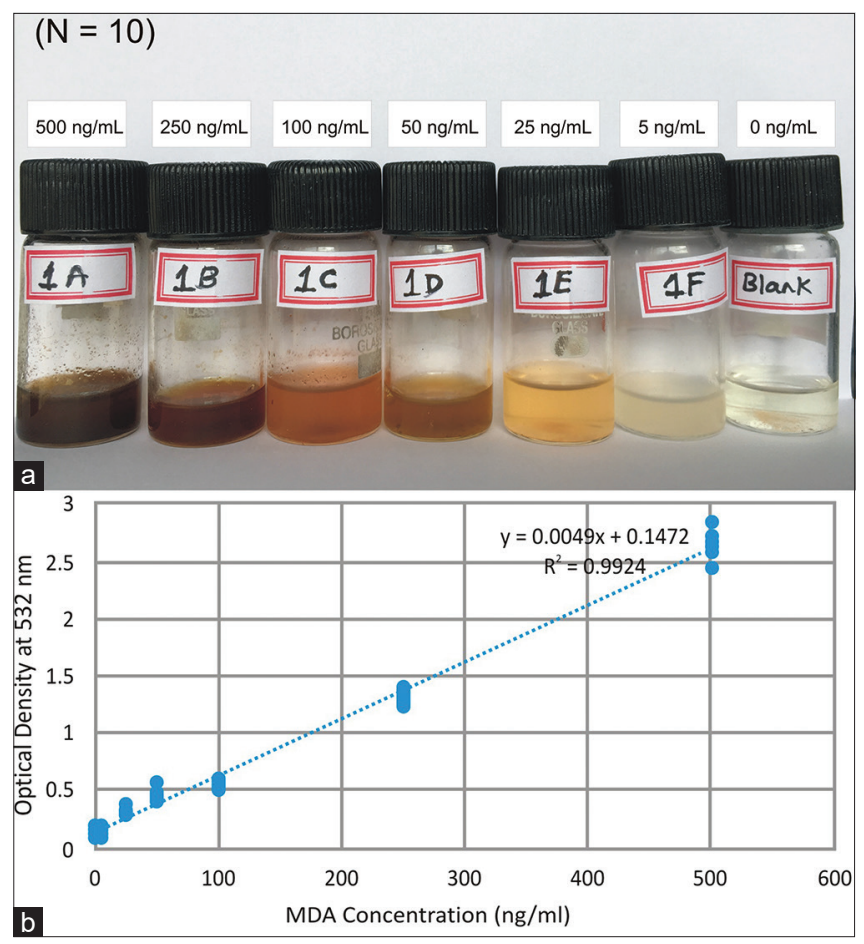

Figure 1: (a) Thiobarbituric acid reaction on malondialdehyde saliva standards of healthy nonsmokers. The color change is observed in a gradient with a being the darkest and $\mathrm{F}$ being the lightest. No color change is seen in the control. (b) The standard curve, plotted based on optical density and malondialdehyde concentration
Testing the method on 500 subjects: The QuitPuff saliva kit was tested on 500 subjects (aged 30-60 years) from two hospitals and a clinic. These subjects were divided into 5 groups. Each group consisted of 100 subjects. Informed consent was obtained from all groups.

\section{Inclusion criteria}

The etiology of oral cancer in India is dominated mainly by tobacco use, alcohol consumption, and smoking. ${ }^{[3-7]}$ As the aim of our study was to investigate the relationship between smoking and oral cancer, subjects with significant alcohol consumption and tobacco chewing habits were excluded.

Nonsmokers $(n=100)$ - No history of alcohol consumption or tobacco chewing habit, average tar content inhaled per day by each subject is $0 \mathrm{mg}$, no comorbidity, and no oral lesions.

Smokers who smoked $<10$ cigarettes per day for a minimum of 5 years $(n=100)$ - No significant alcohol consumption or tobacco chewing habit, average tar content inhaled per day by each subject is $120 \mathrm{mg}$, no comorbidity, and no oral lesions.

Smokers who smoked 10-20 cigarettes per day for a minimum of 5 years $(n=100)$ - No significant alcohol consumption or tobacco chewing habit, average tar content inhaled per day by each subject is $180 \mathrm{mg}$, no comorbidity, and no oral lesions.

Smokers who smoked above 20 cigarettes per day for a minimum of 5 years $(n=100)$ - No significant alcohol consumption or tobacco chewing habit, average tar content inhaled per day by each subject is $240 \mathrm{mg}$, no comorbidity, and no oral lesions.

Smokers who smoked 10-20 cigarettes per day for a minimum of 5 years with recently diagnosed precancerous mouth lesions and oral cancer Stage 1-2 yet to start on treatment $(n=100)$ - No significant alcohol consumption or tobacco chewing habit, average tar content inhaled per day by each subject is $180 \mathrm{mg}$, oral lesions present, oral

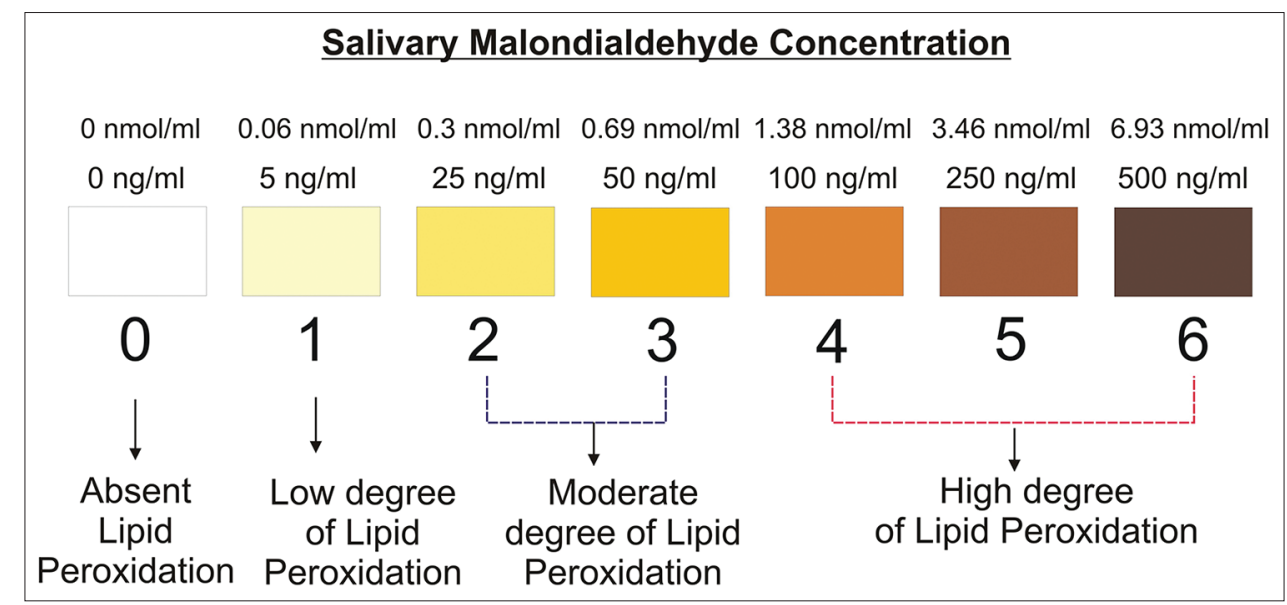

Figure 2: The colorimetric LPI chart. The numbers from 0 to 6 denote the LPI. Interpretation of Results: LPI 0 denotes-no risk; LPI 1 denotes-low risk; LPI 2-3 denotes-moderate risk; LPI 4-6 denotes-high risk. LPI - Lipid peroxidation index 
erosive lichen planus, $n=48$; oral leukoplakia (raised, indurated, white lesion in the oral mucosa more than $5 \mathrm{~mm}$ in diameter with dysplastic changes in the epithelium), $n=24$; submucous fibrosis, $n=8$; and oral squamous cell carcinoma (OSCC), $n=20$. Of the twenty subjects with OSCC, sixteen were diagnosed with Stage 1 OSCC and four were diagnosed with Stage 2 OSCC.

\section{Exclusion criteria}

Patients with chronic alcohol addiction, tobacco chewing habits, and patients with advanced stages of oral squamous cell carcinoma and/or already on treatment or operated upon were excluded from the study.

The tests were performed on fresh samples of saliva. Subjects were asked not to eat, drink, smoke, or chew tobacco an hour before the collection. Subjects rinsed their mouths with $10 \mathrm{~mL}$ of water and thereafter saliva was collected in sterile bottles. The QuitPuff TBA reaction was performed as previously described. The color change was matched with the colorimetric chart [Figure 2] and the LPI was noted.

Validation by ultraviolet visible spectroscopy, the gold standard for the test

For further validation, all 500 samples were sent for MDA determination through UV Spectroscopy (Supporting Information). The readings of UV visible spectroscopy were then plotted on the standard curve and the linear equation $(\mathrm{Y}=0.0049 \mathrm{X}+0.1472)$ was used to determine the MDA concentration values. A Spearman's correlation analysis was performed to understand the correlation between the color change in the samples and the readings of UV visible spectroscopy. On the basis of the MDA concentration, the LPI was again derived and noted. A detailed report of these 500 samples, including photos, UV spectroscopy results, MDA concentrations, and LPI classification, is available in this article's Supporting Information.

\section{Statistical analysis used}

A Spearman's correlation analysis was performed to understand the correlation between the color change in the samples produced by the QuitPuff reaction and the readings of UV visible spectroscopy. A Student's $t$-test was performed to determine the difference in the mean LPI in each of the smoker's group as compared to the nonsmoker's group.

\section{Results}

The mean LPI of nonsmokers was 0.26. In the smoker's group, the mean LPI of smokers who smoked $<10$ cigarettes a day was 2.43, that of smokers who smoked 10-20 cigarettes a day was 3.43 , and that of smokers who smoked more than 20 cigarettes a day was 4.12 . The mean LPI of smokers with oral precancer and oral squamous cell carcinoma was 4.34 [Table 2].
The mean LPI was consistently and significantly elevated $(P<0.001)$ in smokers with oral precancer and cancer and smokers who smoked more than 20 cigarettes a day, 10-20 cigarettes a day, and $<10$ cigarettes a day as compared to nonsmokers.

The mean LPI obtained by QuitPuff colorimetric method was compared with the mean LPI obtained by the validation method of UV spectroscopy. The mean LPIs from both methods were in agreement [Table 2]. Results of the Spearman's correlation indicated that there was a significant positive association between the color changes obtained by QuitPuff method and the readings of the UV spectroscopy $(r=0.93, P<0.001)$.

Among smokers, 96 of 100 smokers with oral precancer and cancer were found to have high degree of LP, an increase compared to that of otherwise healthy smokers $(83 / 100$ subjects who smoked more than 20 cigarettes a day, 65/100 who smoked 10-20 cigarettes a day, and 35/100 who smoked $<10$ cigarettes a day). In contrast, in the nonsmoker's group, 82 of 100 subjects $(82 \%)$ had no detectable LP, and none showed a high degree of LP [Table 3].

Smokers exhibited greater degree of salivary LP as compared to nonsmokers and heavier the smoker, greater was the degree of salivary LP [Table 3].

\section{Discussion}

Cancer is caused by the accumulation of multiple lesions occurring in a single cell. It can be described by three stages: initiation, promotion, and progression. Previous reports indicate that ROS not only initiate but also promote multistep carcinogenesis. ${ }^{[10]}$ ROS-induced LP is implicated in the pathogenesis of oral cancer. ${ }^{[9-13]} \mathrm{MDA}$ is the end product and the most widely studied product of LP. ${ }^{[9-13]}$ By measuring the level of salivary MDA, we can determine the degree of salivary LP and thereby assess the risk of a smoker developing oral precancer and oral cancer.

In our study, smokers with oral precancer and oral squamous cell carcinoma were found to have a higher degree of salivary LP as compared to nonsmokers. Within the smoker's category, the heavier the smoker, the greater the degree of salivary LP. This is in line with other studies, ${ }^{[9-13]}$ on oral precancer and cancer, which have reported similar findings, validating the relationship between free radical activity, LP, and cancer.

We have also observed in our study that saliva can be used as a suitable diagnostic medium, as its collection is easy, noninvasive, not time-consuming, and inexpensive. Our findings are thus in accordance with studies that have shown that salivary MDA could serve as a potential diagnostic marker in potentially malignant disease and OSCC. ${ }^{[9,10,12-15]}$ Our diagnostic test was able to detect the salivary MDA level as an indicator of the degree of LP in the saliva of smokers, precancerous mouth lesions, and 
Table 2: Comparison of mean lipid peroxidation indexes between two methods

\begin{tabular}{lccc}
\hline Group name & $\boldsymbol{n}$ & $\begin{array}{c}\text { Mean LPI derived by colorimetric } \\
\text { method }\end{array}$ & $\begin{array}{c}\text { Mean LPI derived by validation method of UV } \\
\text { Spec }\end{array}$ \\
\hline Non-smokers & 100 & $0.26 \pm 0.52$ & $0.23 \pm 0.50$ \\
Smokers <10 cigarettes/day & 100 & $2.43 \pm 1.60$ & $2.46 \pm 1.66$ \\
Smokers 10-20 cigarettes/day & 100 & $3.43 \pm 1.73$ & $3.44 \pm 1.75$ \\
Smokers >20 cigarettes/day & 100 & $4.12 \pm 1.53$ & $4.18 \pm 1.55$ \\
Smokers with recent oral precancer \& & 100 & $4.34 \pm 0.74$ & $4.37 \pm 0.69$ \\
cancer lesions (stage 1-2) & & &
\end{tabular}

\begin{tabular}{|c|c|c|c|c|c|}
\hline Group name & $n$ & Zero & Low & Moderate & High \\
\hline Non-smokers & 100 & 82 & 18 & 4 & 0 \\
\hline Smokers $<10$ cigarettes/day & 100 & 22 & 9 & 34 & 35 \\
\hline Smokers $10-20$ cigarettes/day & 100 & 12 & 5 & 18 & 65 \\
\hline Smokers $>20$ cigarettes/day & 100 & 9 & 2 & 6 & 83 \\
\hline Smokers with recent oral precancer \& cancer lesions (stage $1-2$ ) & 100 & 0 & 0 & 4 & 96 \\
\hline
\end{tabular}

OSCC patients with $97 \%$ accuracy, and therefore could serve as an early, safe, noninvasive test for smokers to assess their risk of developing oral precancer and cancer.

The simplicity of the procedure does not rule out scope for systematic errors. Inappropriate saliva collection, contamination, or possible degradation of saliva after collection, as well as errors in measurement of saliva or reagent and inconsistent temperatures of the water bath, could lead to false positive results. One way to overcome these errors would be to repeat the test on different occasions. Furthermore, as the test is colorimetric, interpretation of results is largely subjective. In application, QuitPuff salivary diagnostic test does not aim to substitute conventional diagnostic tests, but is meant to act as an qualitative, self-diagnostic test for flagging early risk, and to be followed by laboratory tests for confirmation of diagnosis.

There is ample awareness that cigarette smoking can lead to cancer. For years, cigarette packets have been portraying images of cancer lesions, but this has not discouraged people from smoking. The number of smokers in India has risen from 79 million in 1998 to 108 million in 2015. ${ }^{[21]}$ As the oral cavity is more accessible to complete examination, it could be used in early detection of oral precancerous and cancerous lesions. The disease however gets detected in the later stages, due to reasons such as lack of knowledge and inaccessibility of medical care. ${ }^{[7]}$ Careful annual examination of the oral cavity in persons above the age of 40 years can result in significant improvement in the rate of early detection of oral cancer with all the therapeutic advantages. However, a great proportion of those at risk of oral cancer do not attend annual health-care checkups. ${ }^{[4]}$

Our aim was to devise a test that could detect the early risk of oral precancer and cancer in smokers. We propose that if such a simple, do-it-yourself, home-based test could be provided with every cigarette pack, more people might be willing to check their risk and make behavioral changes prior to the development of oral cancer. More people taking these tests would mean more people finding out their risks in the early stages. Early detection could enable better treatment outcome and improvement in the quality of life. It could reduce health-care costs and the economic burden of treating oral cancer. The test kit requires no elaborate storage conditions and could be easily transported to remote locations and stored in small pan-beedi shops (tobacco selling shops and kiosks) in rural areas. At per sample cost of Rs. 38.15, it could offer an inexpensive and affordable option especially to the lower income populations, where such a test is often most needed. On account of its simplicity, noninvasive nature, low-cost, and easy accessibility, QuitPuff may have great potential as a point-of-care test for oral precancer and oral cancer. The test could be useful as a mass screening tool not only for routine clinics, but also for rural areas and remote locations with limited laboratory facilities or minimally trained health workers.

\section{Conclusion}

On comparing results from the both methods, i.e., the QuitPuff colorimetric method and the validation method of UV spectroscopy, it was found that only 20 of 500 (4\%) resulted in misclassification error. Thus, QuitPuff was able to detect the degree of salivary LP with $96 \%$ accuracy. QuitPuff has great potential as a mass screening tool for early risk detection of oral precancer and cancer in smokers, to be followed up with confirmatory laboratory tests such as biopsies and MRI and CT Scans.

\section{Financial support and sponsorship}

Nil.

\section{Conflicts of interest}

There are no conflicts of interest. 


\section{References}

1. Bano S, David MP, Indira AP. Salivary biomarkers for oral squamous cell carcinoma: An overview. IJSS Case Rep Rev 2015;1:39-45.

2. Markopoulos AK, Michailidou EZ, Tzimagiorgis G. Salivary markers for oral cancer detection. Open Dent J 2010;4:172-8.

3. Gupta B, Ariyawardana A, Johnson NW. Oral cancer in India continues in epidemic proportions: Evidence base and policy initiatives. Int Dent J 2013;63:12-25.

4. Feller L, Lemmer J. Oral squamous cell carcinoma: Epidemiology, clinical presentation and treatment. J Cancer Ther 2012;3:263-8.

5. Krishna Rao SV, Mejia G, Roberts-Thomson K, Logan R. Epidemiology of oral cancer in Asia in the past decadean update (2000-2012). Asian Pac J Cancer Prev 2013;14:5567-77.

6. Lin WJ, Jiang RS, Wu SH, Chen FJ, Liu SA. Smoking, alcohol, and betel quid and oral cancer: A prospective cohort study. J Oncol 2011;2011:525976.

7. Mehrotra R, Yadav S. Oral squamous cell carcinoma: Etiology, pathogenesis and prognostic value of genomic alterations. Indian J Cancer 2006;43:60-6.

8. Shah FD, Begum R, Vajaria BN, Patel KR, Patel JB, Shukla SN, et al. A review on salivary genomics and proteomics biomarkers in oral cancer. Indian J Clin Biochem 2011;26:326-34.

9. Shetty SR, Babu S, Kumari S, Shetty P, Hegde S, Castelino R. Status of salivary lipid peroxidation in oral cancer and precancer. Indian J Med Paediatr Oncol 2014;35:156-8.

10. Rai B, Kharb S, Jain R, Anand SC. Salivary lipid peroxidation product malonaldehyde in various dental diseases. World J Med Sci 2006;1:100-1.

11. Ganesan A, Kumar N G. Assessment of lipid peroxides in multiple biofluids of leukoplakia and oral squamous cell carcinoma patients - A clinico- biochemical study. J Clin Diagn Res 2014;8:ZC55-8.

12. Arathi A, D'Souza B, Sayanthan M, Raksha S, Buthesh GA, Jisha K, et al. Salivary malondialdehyde and antioxidant status in oral squamous cell carcinoma patients and smokers. Biomed Res 2010;21:67-70.

13. Shivashankara AR, Kavya PM. Salivary total protein, sialic acid, lipid peroxidation and glutathione in oral squamous cell carcinoma. Biomed Res 2011;22:355-9.

14. Kaur J, Politis C, Jacobs R. Salivary 8-hydroxy-2-deoxyguanosine, malondialdehyde, vitamin $\mathrm{C}$, and vitamin $\mathrm{E}$ in oral pre-cancer and cancer: Diagnostic value and free radical mechanism of action. Clin Oral Invest 2016;20:315-9.

15. Abdolsamadi H, Rafieian N, Goodarzi MT, Feradmal J, Davoodi P, Jazayeri $\mathrm{M}$, et al. Levels of salivary antioxidant vitamins and lipid peroxidation in patients with oral lichen planus and healthy individuals. Chonnam Med J 2014;50:58-62.

16. Ohkawa $\mathrm{H}$, Ohishi N, Yagi K. Assays for lipid peroxides in animal tissues by thiobarbituric acid reaction. Anal Biochem 1979;95:351-8.

17. Buege JA, Aust SD. Microsomal lipid peroxidation. Methods Enzymol 1978;52:302-10.

18. Esterbauer H, Cheeseman KH. Determination of aldehydic lipid peroxidation products: Malonaldehyde and 4-hydroxynonenal. Methods Enzymol 1990;186:407-21.

19. Uchiyama M, Mihara M. Determination of malondialdehyde precursor in tissues by thiobarbituric acid test. Anal Biochem 1978;86:271-8.

20. Asakawa T, Matsushita S. Coloring condition of thiobarbituric acid test for detecting lipid hydroperoxides. Lipids 1980;15:137-40.

21. Mishra S, Joseph RA, Gupta PC, Pezzack B, Ram F, Sinha DN, et al. Trends in bidi and cigarette smoking in India from 1998 to 2015 , by age, gender and education. BMJ Glob Health 2016;1:e000005. 